the university education of technical people is not a sufficient answer, although some of that will be needed. More to the point is the need that Europe, in trying to create the foundations for industrial prosperity in the next century, should find some way of enabling the now-young people who will inhabit that world to make their full mark. In many ways, Europe has grown too old.

The third need for the summit is to remember Adam Smith. Inward-looking Europeans see their enterprise as a selfcontained imitation of what has already happened elsewhere. Too many Europeans consider that the immediate goal must be to replicate what IBM and AT\&T have done in the United States, or what a host of Japanese companies have done in consumer electronics. The fallacy is that success would merely bring the prospect of head-on competition in fields that are certain to seem old-fashioned even a decade from now. But there is no reason why the world should become less interdependent than it is already, for which reason the trick for Europe must be that prosperity should rest on industrial activities complementary to those elsewhere. That is why the objective of those who endorse Eureka should be to build on Europe's present strengths, such as they are, not simply to imitate what others do. The goal must be an economic and economical division of labour, to which end originality is the crying need. Will the summit have the courage to recognize that simple but daunting truth?

\section{How many (what) miles?}

\section{Last week's shuttle flight shows that the Strategic Defense Initiative has a lot to learn.}

THE timing of last week's fiasco in which a laser beam from Hawaii was directed at the wrong side of the US shuttle in orbit about the Earth could hardly have been worse. The US Congress is at the stage in the annual budget cycle when critics of the Strategic Defense Initiative (SDI) are energetically - and successfully - chipping away at the huge budget the administration has asked for. While nothing is settled, the chances are that the budget for the financial year beginning on 1 October will be reduced by between a quarter (according to the Senate) and a third (according to the House of Representatives) from the $\$ 3,700$ million asked for. If the managers of SDI are wise, they will spend at least some of that sum on teaching each other a little about elementary goedesy.

The official explanation of the first failure of the laser test (which worked on later orbits) is quite breathtaking in its innocence. Almost merrily, the spokespeople have been saying that, by some oversight, the "on-board" computer on the shuttle had been programmed "in" statute rather than nautical miles. By their nudges and winks, thay have implied that only some profound perversity can explain the habit that has people who travel in shuttles measuring distance in the maritime measure of nautical miles. No doubt SDI officials will have figured out that nautical implies something to do with the sea, because Nautilus is a kind of submarine. In their innocence, they seem not to know that a nautical mile is intended to be the length of a minute of arc along a great circle on the surface of the Earth, although it was prematurely defined as 6,080 feet by the British Admiralty in the eighteenth century.

The SDI people are unlikely to be too downcast by this show of ignorance; they have earned a reputation for being brash. They have a tendency, when they encounter physical problems that would seem insuperable obstacles to others, to make a solution of them a "requirement" of the SDI programme as a whole. The little confusion between statute and nautical miles may, in any case, make them seek safety in unambiguously named kilometres instead (a cause too long dormant in the United States). So perhaps they should be told that the French Revolution had a committee, of which both Laplace and Lagrange were members, which defined the kilometre in much the same way as the nautical miles as one ten-thousandth of the distance between the Equator and the pole.

\title{
Laser proliferation
}

The US Department of Energy thinks the laser enrichment of uranium feasible; that is bad news. THE third review conference of the non-proliferation treaty (NPT), due to open at Geneva in August, will be forced to reckon with a late agenda item, the recognition that the simplest way of making nuclear weapons is probably now the enrichment of uranium by means of lasers. That is the implication of what appears to have been a successful demonstration of laser enrichment at the US Lawrence Livermore National Laboratory in California. The laboratory has been able to make five kilograms of uranium-235 in a single purification step. For those who wish to make bombs, the advantages of this route are obvious. Unlike isotope separation by gaseous diffusion or centrifugation, laser separation may be a once-through process. So capital costs are likely to be less and, for potential violators of agreements, separation plants will be inconspicuous.

None of this implies that uranium enrichment has become child's play. At Los Alamos as well as at Livermore, people have been trying for at least a decade to distinguish by means of lasers between the different isotopes of particular elements, with uranium usually at the backs of their minds. The fact that success has eluded them for so long is one comfort, suggesting that governments will not be able to run up material for a few bombs overnight by buying standard equipment from commercial suppliers. Indeed, the technology of copper excimer lasers reported (see p.706) to be the primary energy source for the Livermore process will not easily be replicated elsewhere, at least for the time being. In any case, crucial details such as the identity of the electronic transitions by means of which uranium atoms are excited to near-ionization are sensibly being kept secret. The obvious snag is that uranium atoms are the same the whole world over, and that the investigation of the spectroscopy of uranium required to specify the ingredients of a laser enrichment machine should be little more than few months' work for a couple of competent physicists. It is a fair guess that even governments with no interest in making bombs, but with an interest in what others may be doing, will put this work in hand immediately. Putative bomb-makers will probably be even quicker off the mark.

So does this new development mean that there is no longer any purpose served by attempts to control the spread of nuclear weapons by the physical control of fissile material? Fortunately, not quite. NPT is a compact between non-nuclear governments and the nuclear powers under which the first group undertakes not to make nuclear weapons, and to put up with physical inspection by the International Atomic Energy Agency, while the second undertakes not to help others make bombs but to help with civil nuclear technology, and at the same time to negotiate measures of arms control that will make the world a safer place. The signatory nuclear powers (France and China have not joined NPT) will be given another drubbing at this year's review conference for having done so little on arms control, but it seems unlikely that non-nuclear powers will desert the treaty on that account, or because laser enrichment seems to offer rivals outside the treaty a more convenient route to bombmaking. Keeping safeguards will be more than ever a demonstration of self denial.

The more serious problems are what they have always been, the abstention from NPT of countries which believe they may gain from being thought potential nuclear powers - Israel, Pakistan and so on. If laser enrichment means anything, it is that governments within NPT should have a powerful incentive not merely to control the use made of fissile material but also to see that the international trade in uranium is also well-regulated. For however convenient the new technique may be, it will still take the best part of a tonne of uranium to extract a critical mass of uranium-235, which should be a noticeable amount of such a scarce material. That is the direction in which the interests of the regulators should now be shifted. 